\title{
Sensorless Vector Control of Closed-slot Induction Machines at Low Frequency
}

\author{
Hisao Kubota ${ }^{* a)}$ Senior Member, Takahiro Yamada* Student Member
}

(Manuscript received March 6, 2012, revised Aug. 4, 2012)

\begin{abstract}
Sensorless vector control for induction motor drives is widely used. However, in the case of mass-produced closedslot motors, it is difficult operate them at zero frequency with regenerative load. In this paper, a sensorless vector control method based on three-phase PWM carrier waves is applied to a mass-produced closed-slot induction motor. Further, methods to improve stability are proposed.
\end{abstract}

Keywords: induction machine, sensorless control, zero frequency, closed slot

\section{Introduction}

Sensorless vector control methods for induction motor drives have been proposed ${ }^{(1)-(7)}$. Most of them are based on the information of the electromotive force, $\mathrm{EMF}^{(1)-(4)}$. These methods are not able to drive induction machines at zero frequency continuously, because the EMF becomes zero.

Some methods are based on the saliency which is caused by the magnetic saturation for open slot or semi-closed slot induction machines ${ }^{(5)(6)}$. Usually, the saliency is detected by injecting high frequency voltages. However, it is difficult for mass-produce closed slot induction motor to detect the saliency. Only a few method successes to drive the closed slot motors ${ }^{(7)}$. Saturation effects in induction machines are associated with the main flux created by the magnetizing current and with leakage flux created by slot currents. With open and semi-closed rotor slot, the leakage flux is not significant. With closed rotor slot, rotor current will tend to drive the slot bridges much further into saturation under loaded conditions. These effects were described in detail in Ref. (6).

In this paper, a sensor-less vector control method based on three phase PWM carrier waves is applied to a mass-produce closed slot induction motor, and stability improvement methods are proposed.

\section{Flux Position Estimation}

For interior permanent magnet synchronous machines sensor-less vector control at low speeds, high frequency voltage injecting methods have been proposed. These methods utilize magnetic saliency. When induction machines have magnetic saliency because of saturation, these methods are applicable. However, mass produce closed slot induction machines have weak saliency, so some methods fails to drive them.

In this paper, the method proposed in Ref. (8) based on three phase PWM carrier waves is applied. When the three

a) Correspondence to: Hisao Kubota. E-mail: kubota@isc.meiji. ac.jp

* School of Science and Technology, Meiji University

1-1-1, Higashi-mita, Tama-ku, Kawasaki 214-8571, Japan phase carrier waves for the PWM pulse generation are chosen as shown in Fig. 1, the carrier frequency components are injected automatically into the stator voltages.

The voltage equation for the PWM carrier frequency component is expressed by the following equation in the $\alpha-\beta$ stationary reference frame.

$$
\left[\begin{array}{c}
v_{\alpha h} \\
v_{\beta h}
\end{array}\right]=\left[\begin{array}{cc}
L_{0}+L_{1} \cos 2 \theta & L_{1} \sin 2 \theta \\
L_{1} \sin 2 \theta & L_{0}-L_{1} \cos 2 \theta
\end{array}\right] \frac{d}{d t}\left[\begin{array}{c}
i_{\alpha h} \\
i_{\beta h}
\end{array}\right]
$$

where $L_{0}=\left(L_{m}+L_{t}\right) / 2, L_{1}=\left(L_{m}-L_{t}\right) / 2, L_{m}$ : flux axis selfinductance, $L_{t}$ : torque axis self-inductance, $\theta$ : Flux position. The sub-script $\mathrm{h}$ means the PWM carrier frequency component.

When the three phase triangular PWM carrier waves are used, the PWM carrier frequency components of the armature voltage are expressed by the following equation.

$$
\left[\begin{array}{l}
v_{\alpha h} \\
v_{\beta h}
\end{array}\right]=V_{h}\left[\begin{array}{c}
\cos \omega_{h} t \\
\sin \omega_{h} t
\end{array}\right]
$$

Substituting Eq. (2) into Eq. (1) and solving about the current under steady state condition, the PWM carrier frequency component of the armature current, $i_{\alpha h}$, is expressed by the following equation.

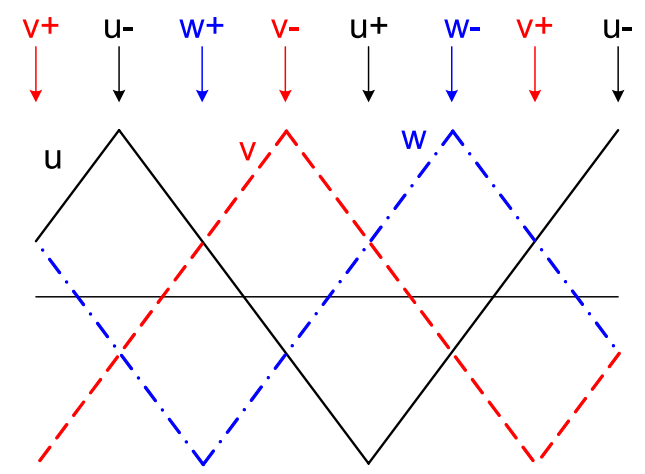

Fig. 1. Three phase triangular PWM carrier waves and current measurement points 


$$
i_{\alpha h}=\frac{V_{h}\left\{\left(L_{0}-L_{1} \cos 2 \theta\right) \sin \omega_{h} t+L_{1} \sin 2 \theta \cdot \cos \omega_{h} t\right\}}{\omega_{h}\left(L_{0}^{2}-L_{1}^{2}\right)}
$$

The stator current is measured at the points shown by arrows in Fig. 1. The u-phase current is detected twice in a cycle of the PWM carrier waves at $\omega_{h} t=0$ and $\omega_{h} t=\pi$. Therefore, the u-phase current at these two points are expressed by the following equation.

$$
i_{u}=i_{u f} \pm \frac{V_{h 1}}{\omega_{h}\left(L_{0}^{2}-L_{1}^{2}\right)} L_{1} \sin 2 \theta .
$$

where $i_{u f}$ is the fundamental component of the u-phase current, $V_{h 1}$ is the transferred value of $V_{h}$ into the $\mathrm{u}-\mathrm{v}-\mathrm{w}$ three phase axis.

The difference between the u-phase currents at $\omega_{h} t=0$ and $\omega_{h} t=\pi$ becomes

$$
\Delta i_{u h}=i_{u}(u+)-i_{u}(u-)=\frac{2 V_{h 1}}{\omega_{h}\left(L_{0}^{2}-L_{1}^{2}\right)} L_{1} \sin 2 \theta \cdots
$$

where $i_{u}(u+)$ and $i_{u}(u-)$ are the $\mathrm{u}$ phase current at the points $\mathrm{u}+$ and $\mathrm{u}-$ shown in Fig. 1 .

The following equations are obtained about the phase $\mathrm{v}$ and $\mathrm{w}$ with the same procedures as the phase $\mathrm{u}$.

$$
\begin{aligned}
\Delta i_{v h} & =\frac{2 V_{h 1}}{\omega_{h}\left(L_{0}^{2}-L_{1}^{2}\right)} L_{1} \sin 2\left(\theta-\frac{2 \pi}{3}\right) \\
\Delta i_{w h} & =\frac{2 V_{h 1}}{\omega_{h}\left(L_{0}^{2}-L_{1}^{2}\right)} L_{1} \sin 2\left(\theta+\frac{2 \pi}{3}\right)
\end{aligned}
$$

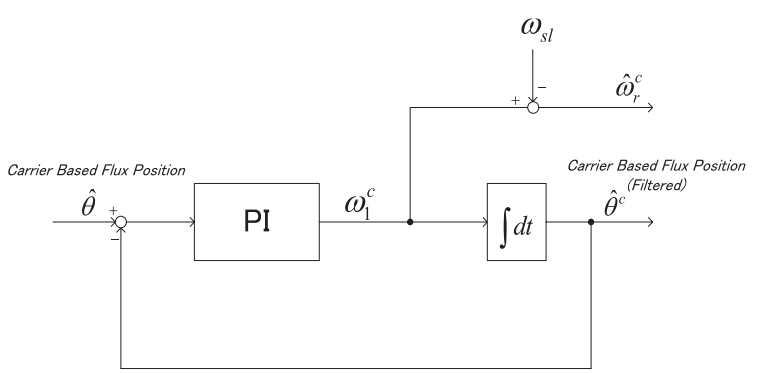

Fig. 2. Block diagram of angular velocity calculation
From $\Delta i_{u h}, \Delta i_{v h}$, and $\Delta i_{w h}$, the following equation is obtained.

$$
\begin{aligned}
{\left[\begin{array}{l}
\Delta i_{\alpha h} \\
\Delta i_{\beta h}
\end{array}\right] } & =\left[\begin{array}{ccc}
1 & -1 / 2 & -1 / 2 \\
0 & \sqrt{3} / 2 & -\sqrt{3} / 2
\end{array}\right]\left[\begin{array}{l}
\Delta i_{u h} \\
\Delta i_{v h} \\
\Delta i_{w h}
\end{array}\right] \\
& =\frac{3}{2} \frac{V_{h 1}}{\omega_{h}\left(L_{0}^{2}-L_{1}^{2}\right)}\left[\begin{array}{c}
\sin 2 \theta \\
\cos 2 \theta
\end{array}\right] \ldots
\end{aligned}
$$

Therefore, the estimated flux position, $\hat{\theta}$, can be calculated through the ratio of $\Delta i_{\alpha h}$ and $\Delta i_{\beta h}$ of Eq. (8) and the arctan function as follows.

$$
\hat{\theta}=\frac{1}{2} \tan ^{-1}\left(\frac{\Delta i_{\alpha h}}{\Delta i_{\beta h}}\right) .
$$

The motor angular velocity, $\hat{\omega}_{r}^{c}$, is calculated as shown in Fig. 2. The stator angular frequency, $\omega_{1}^{c}$, is obtained from the flux position, $\hat{\theta}$, by using the PLL technique. The motor angular velocity is obtained by subtracting the slip angular frequency, $\omega_{s l}$, as follows.

$$
\hat{\omega}_{r}^{c}=\omega_{1}^{c}-\omega_{s l}
$$

The slip angular frequency is calculated by using the torque current component, $i_{t}^{*}$, and the magnetizing current component, $i_{m}^{*}$, as follows.

$$
\omega_{s l}=\frac{i_{t}^{*}}{\tau_{2}\left(\frac{1}{1+\tau_{2} p}\right) i_{m}^{*}}
$$

where $\tau_{2}=\frac{L_{2}}{R_{2}}, p=\frac{d}{d t}$.

The block diagram of a control system is shown in Fig. 3.

\section{Flux Strengthening Control}

Ratings of the tested induction machine are shown in Table 1. The tested machine is a mass produce closed slot motor made by Fuji Electric Co.

Fig. 4 shows experimental results of speed control with the proposed method. The torque of the load machine connected with the tested induction machine is controlled. The speed command is constant at $10 \mathrm{rad} / \mathrm{s}$ (3.3\% of the rated speed).

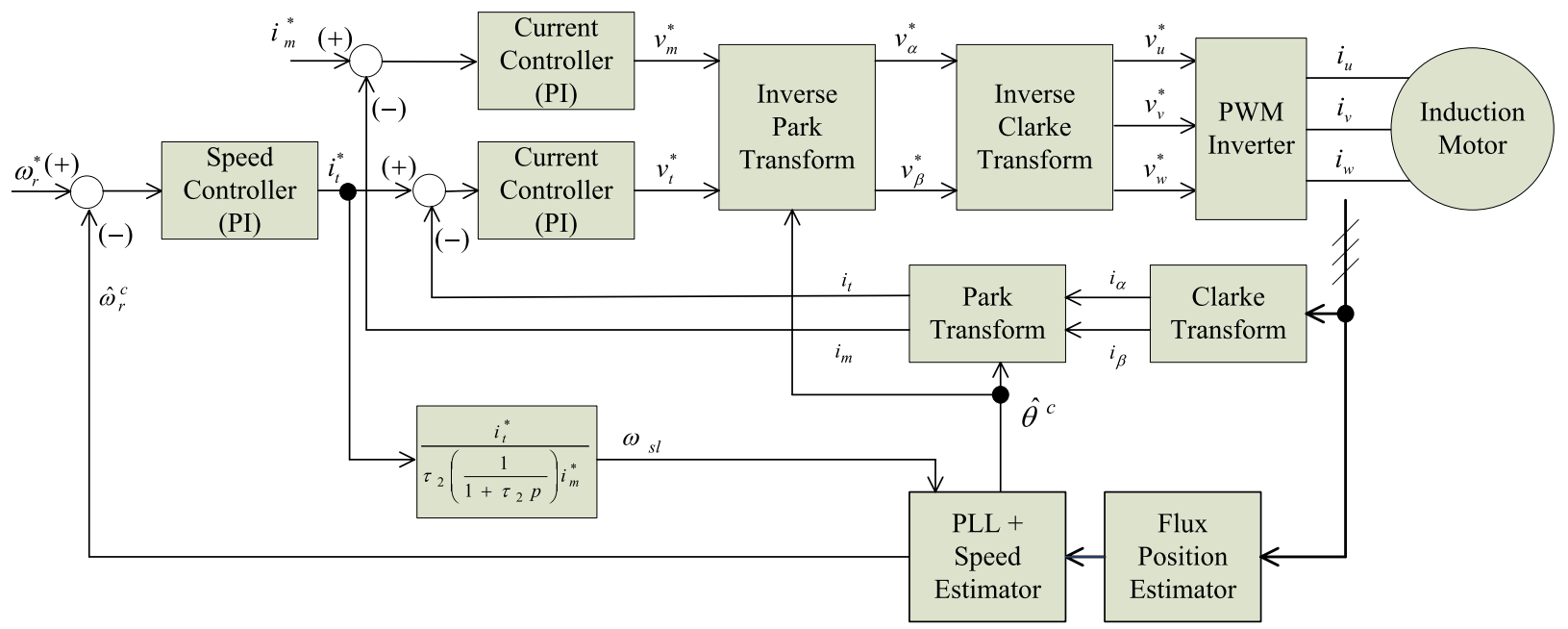

Fig. 3. Block diagram of proposed sensorless vector control system 
Table 1. Ratings of tested induction machine

\begin{tabular}{|c|c|c|c|}
\hline Output Power & $2.2 \mathrm{~kW}$ & Stator Voltage & $200 \mathrm{~V}$ \\
\hline Stator Current & $9.2 \mathrm{~A}$ & Poles & 4 \\
\hline Frequency & $50 \mathrm{~Hz}$ & Revolution & $1430 \mathrm{~min}^{-1}$ \\
\hline
\end{tabular}

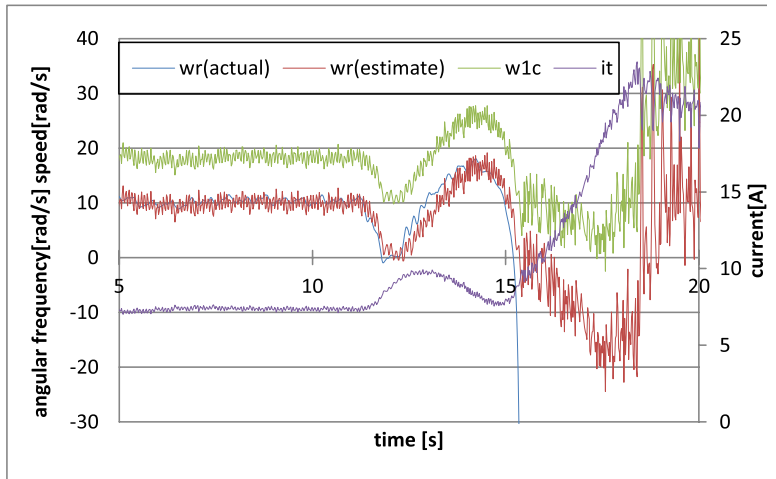

(a) powering mode

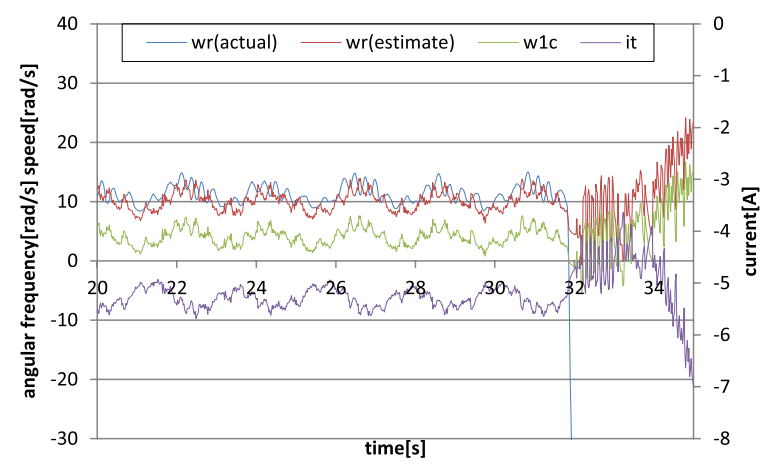

(b) regenerating mode

Fig. 4. Experimental result for sensorless speed control Speed command: $10 \mathrm{rad} / \mathrm{s}$ (Electric), Load torque: From $60 \%$ to $65 \%$, Step change

The PWM carrier frequency is set at $1,200 \mathrm{~Hz}$, which is relatively low for precise measurements of the phase current differential. The system is operating stably when the load torque is $60 \%$ of the rated value. However, it becomes unstable when the load torque increases to $65 \%$. The reason of the instability is thought that the flux position estimation is affected by the torque current component and the estimated position becomes incorrect. Fig. 5 shows the loci of $\Delta i_{\alpha h}$ and $\Delta i_{\beta h}$ under no load and $60 \%$ load conditions. The radius of the loci for the $60 \%$ load torque is much larger than that for no load. It means that the torque current component affects the inductance value.

To solve the instability, we propose the flux strengthening control. Fig. 6 shows the mutual inductance and the rotor flux linkage calculated from no-load test and locked rotor test. The rated $(100 \%)$ points are marked in the figures. By strengthening the flux level, the saturation level becomes deeper. So the influence of the torque current component becomes weak. Considering that the system is stable at $60 \%$ load torque with $100 \%$ magnetizing current, we tried to increase the magnetizing current to $150 \%$, marked in Fig. 6, for full load torque operation.

Fig. 7 shows the experimental results with the flux strengthening control. The magnetizing current component is increased to $150 \%$ of the rated value. The speed command

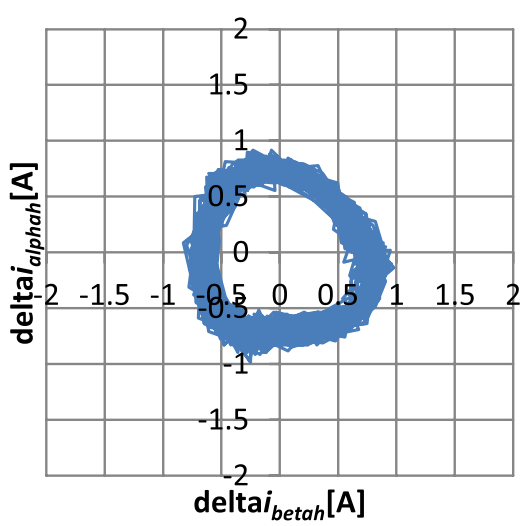

(a) No Load

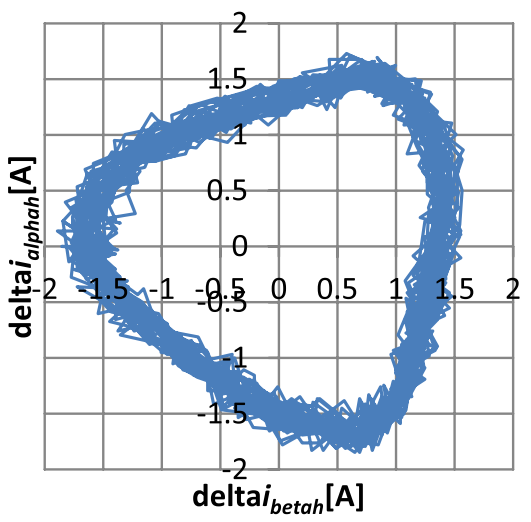

(b) $60 \%$ Load Torque(regenerative)

Fig. 5. $\Delta i_{\alpha h}$ and $\Delta i_{\beta h}$ at $100 \%$ Magnetizing Current, $10 \mathrm{rad} / \mathrm{s}$

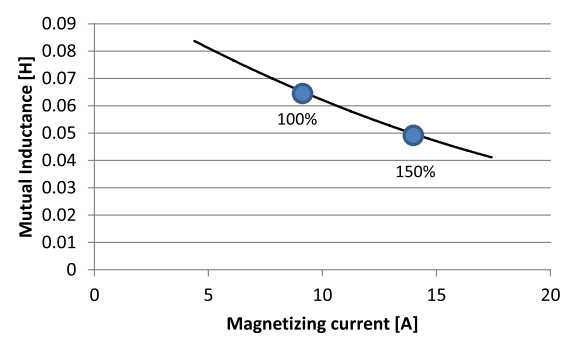

(a) Mutual Inductance

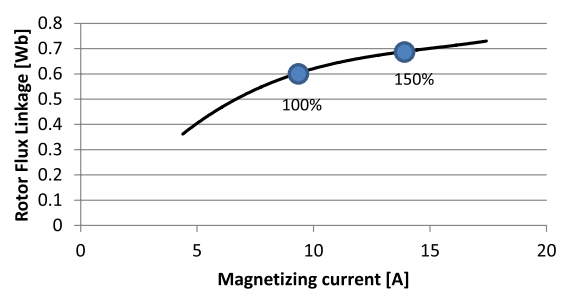

(b) Rotor Flux Linkage

Fig. 6. Mutual inductance and flux linkage vs. magnetizing current

is $10 \mathrm{rad} / \mathrm{s}$ and the load torque is $100 \%$. The system is operating stably under powering condition with full load torque.

\section{Regenerating Operation}

When the induction machines are coupled with regenerative load, the synchronous speed becomes lower than the motor speed. So, the stator frequency might be zero. Electromotive force based methods are not applicable to zero frequency condition with regenerative load continuously. 


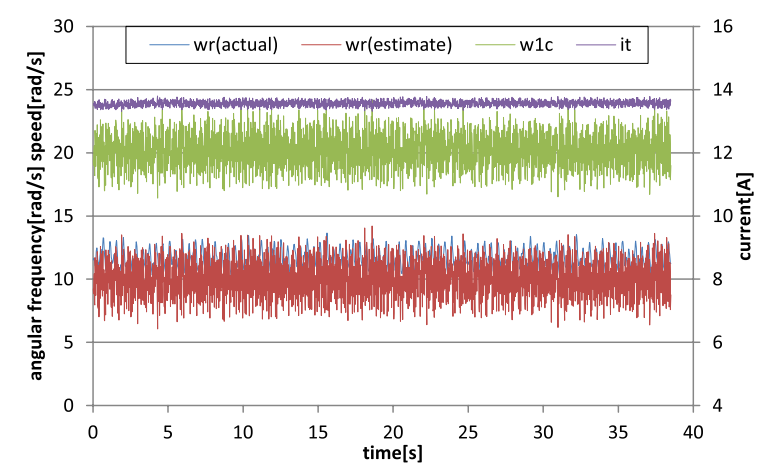

Fig. 7. Experimental results of speed control with flux strengthening control, powering mode, Speed command: $10 \mathrm{rad} / \mathrm{s}$ (Electric) Load torque: $100 \%$

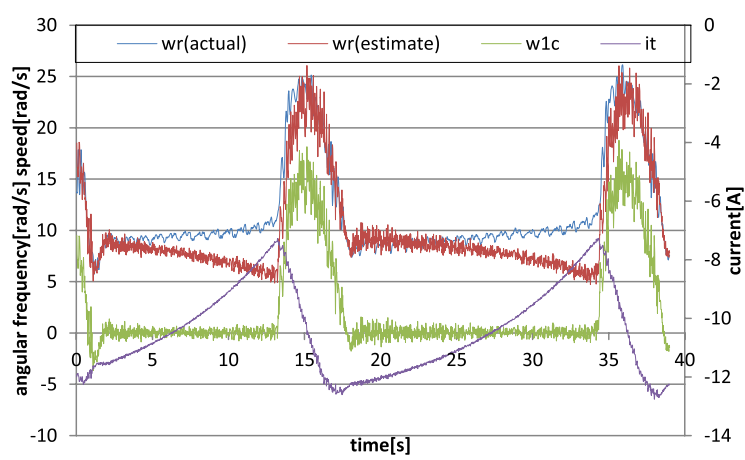

Fig. 8. Experimental results of speed control with flux strengthening control,regenerating mode, Speed command: $10 \mathrm{rad} / \mathrm{s}$ (Electric) Load torque: 100\%

Fig. 8 shows experimental results for speed control. The speed command is $10 \mathrm{rad} / \mathrm{s}$ and the load torque is $100 \%$, which is regenerative torque. The motor speed fluctuates. The synchronous speed or the stator frequency is zero for a while. At zero frequency, the torque current component is increasing, and the actual speed reaches the speed command (around 10s, and 30s). However, estimated speed is decreasing during zero frequency. From this experiment, it is found that the rated torque can be generated, but the estimated speed is incorrect at zero frequency with regenerative load. So it is difficult to control the motor speed precisely around zero frequency.

Considering above phenomenon, we propose variable gain PI speed controller. Fig. 8 indicates that the integral action of the PI speed controller triggers the fluctuation. So, the gain of the integral component of the speed controller is reduced around zero frequency as shown in Fig. 9. The threshold value, $\Delta \omega$, is set at $3 \mathrm{rad} / \mathrm{s}$, which is decided experimentally.

Fig. 10 shows experimental results with the variable PI gain. The speed command and the load torque are the same as those of Fig. 8. Although there is small steady state error between the speed command and the actual value, the system is operating stably. The proposed system generates rated torque at zero frequency successfully.

Fig. 11 shows experimental results for speed step responses. At first, the speed command is set at $10 \mathrm{rad} / \mathrm{s}$, the stator frequency and the integral gain are about zero. After the speed command is changed, the integral gain increases quickly.

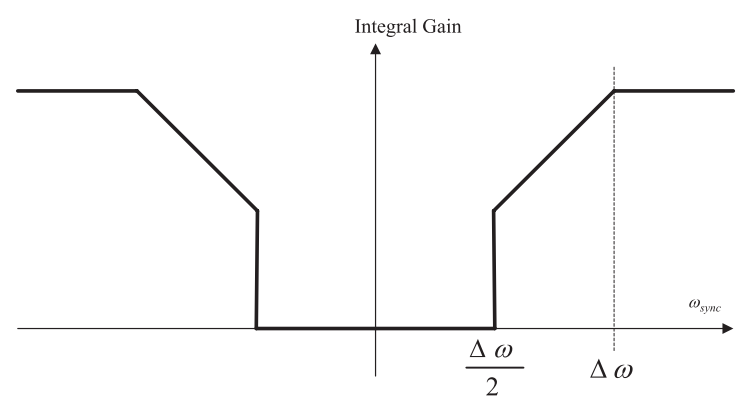

Fig. 9. Integral gain of speed controller around zero frequency

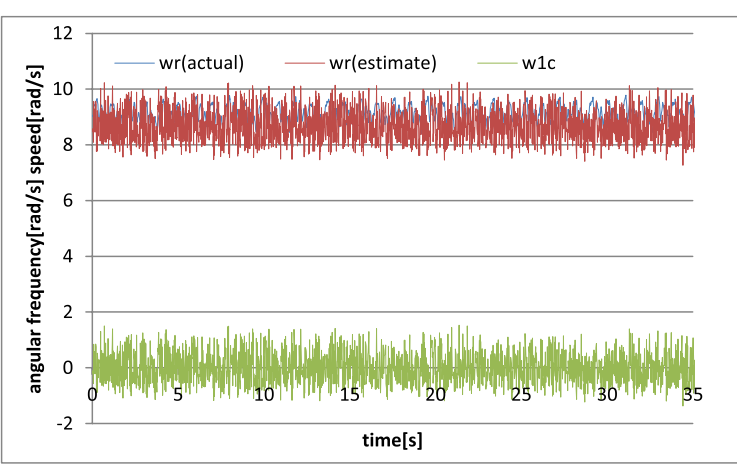

Fig. 10. Experimental results of speed control with variable gain, Speed reference: $10 \mathrm{rad} / \mathrm{s}$ Load torque: $100 \%$

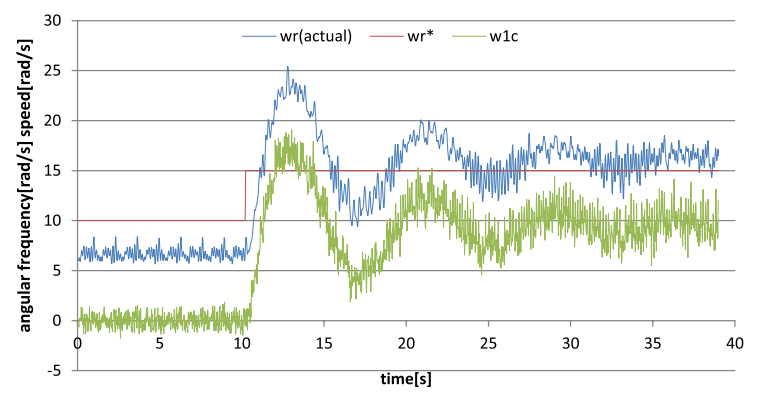

(a) angular frequency and speed

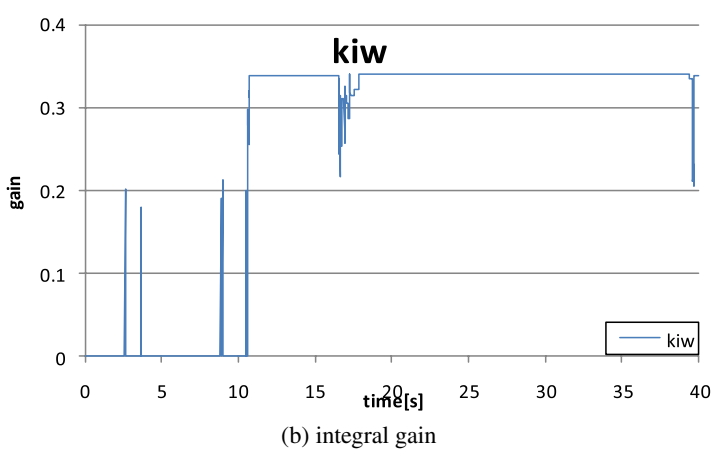

Fig. 11. Experimental results of speed control with variable gain, Speed reference: $10 \mathrm{rad} / \mathrm{s}$ to $15 \mathrm{rad} / \mathrm{s} \mathrm{Load}$ torque: $85 \%$

\section{Conlusion}

Sensorless vector controls for induction machines injecting high frequency components have been proposed. These methods are easily applied to open slot and semi-closed machines. However, it is difficult to apply them to the closed slot machine, because the torque current components heavily 
affect the magnetic saliencies.

In this paper, a sensorless vector control method utilizing high frequency components based on the three phase PWM carrier waves is applied to the closed slot induction machine. To solve some instabilities, the flux strengthening and variable integral gain of the speed controller are introduced. The validity of the proposed method is verified experimentally.

\section{References}

( 1 ) H. Kubota, M. Ozaki, K. Matsuse, and T. Nakano: "Direct Field Oriented Control of Induction Motor without Speed Sensors using Adaptive Flux Observer", IEEJ Trans. IA, Vol.111-D, No.11, pp.954-960 (1991)

( 2 ) H. Tajima, G. Guidi, and H. Umida: "Consideration About Problems and Solutions of Speed Estimation Method and Parameter Tuning for SpeedSensorless Vector Control of Induction Motor Drives", IEEE Trans. IA, Vol.38, No.5, pp.1282-1289 (2002)

( 3 ) T. Hamajima, M. Hasegawa, S. Doki, and S. Okuma: "Sensorless Vector Control of Induction Motor Stabilized at the Whole Region with Speed and Stator Resistance Identification based on Augmented Error", IEEJ Trans. IA, Vol.124, No.8, pp.750-759 (2004)

( 4 ) T. Tateyama, T. Ohba, and H. Kubota: "Speed Estimation and Stator Resistance Estimation of Induction Machines Using Estimation Error Index and Stability Consideration", IEEJ Trans. IA, Vol.129, No.8, pp.794-801 (2009)

( 5 ) M. Schroedl, D. Hennerbichler, and T.M. Wolbank: "Induction Motor Drive for Electric Vehcles without Speed- and Position Sensors", Proc. European Power Electronics Conf. (EPE), pp.271-275 (1993)

( 6 ) P.L. Jansen and R.D. Lorenz: "Transducerless position and velocity estimation in induction and salient AC machines", IEEE Trans. IA, Vol.31, No.2, pp.240-247 (1995)

( 7 ) K. Ide, I. Murokita, M. Sawamura, M. Ohto, Y. Nose, J.I. Ha, and S.K. Sul: "Finite element analysis of sensorless induction machine by high frequency voltage", Proc. Int. Power Electronics Conf. (IPEC), pp.1842-1847 (2000)

( 8 ) H. Kubota, S. Nakagawa, and T. Kobayashi: "Sensorless Vector Control of IPMSM with DC Link Current Measurement at Low Speed", IEEJ Trans. IA, Vol.128, No.4, pp.537-542 (2008)

Hisao Kubota (Senior Member) received the B.E., M.E., and Ph.D.

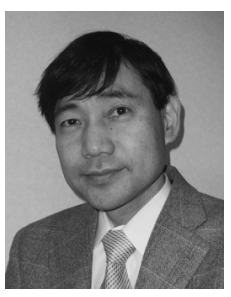
degrees in electrical engineering from Meiji University, Japan, in 1982, 1984, and 1989, respectively. Since 1984, he has been a member of the faculty at Meiji University, where he is currently a Professor. His research interests are in motor drives. Dr. Kubota is a member of the Institute of Electrical Engineers of Japan. He is also a member of the IEEE Industry Applications, Industrial Electronics, and Power Electronics Societies.

Takahiro Yamada (Student Member) was born on November $11^{\text {th }}$,

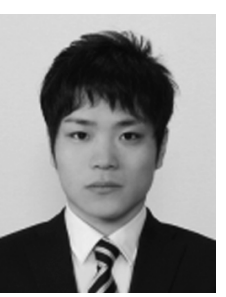

1987. He received the B.E. degree in Engineering from Meiji University in 2010. He is a student of the Master course of Meiji University. His research interests are in motor drives. 